\title{
Editorial
}

\section{An Indian perspective on the challenges in global health financing}

\author{
K. SUJATHA RAO* \\ Former Union Secretary, Ministry of Health \& Family Welfare, Government of India, Hyderabad, Telengana State, India
}

In 2012, the Chatham House established a Working Group on Health Financing, of which I was a member, to deliberate on a global framework for health financing (Røttingen et al., 2014) (reference to paper by McIntyre et al., 2017). Intensive discussions and exhaustive studies brought out 20 recommendations. Of them three were important points emphasizing the need for countries to (i) ensure a minimum public spending of USD 86 per capita and at least $5 \%$ of the country's gross domestic product (GDP) for providing universal access to a package of essential health services; (ii) explore the scope available to mobilize domestic resources through better management; and (iii) shift focus in international cooperation toward health system strengthening that enhances equity. Read together these recommendations call on nation states to shift their attention toward enhancing public welfare by prioritizing health in their development agenda and demonstrating a greater political will to do whatever needs to be done. The articles in this volume provide a detailed exposition of these findings, that if implemented, could lead to a profound reduction in the overall global burden of disease.

It is illustrative to evaluate the applicability of these critical recommendations to a country like India that accounts for almost a fifth of the global disease burden. India ranks among 15 countries in the world where public spending on health is about $1 \%$ of the GDP. Such a level of spending has been constant in India over the past seven decades, whether its annual GDP growth rate was less than $3 \%$ or over $7 \%$. As per the latest estimates, India spends $4.0 \%$ of its GDP on health or USD 54 per capita. Of this, only $1.2 \%$ of GDP or USD $16 \%$ is public spending, while $2.7 \%$ of GDP or USD 37 per capita is out-of-pocket expenditure. Such regressive spending patterns help explain India's inability to contain disease and improve population health. These levels and this pattern of spending also explain why

\footnotetext{
*Correspondence to: K. Sujatha Rao, Former Union Secretary, Ministry of Health \& Family Welfare, Government of India, Plot 153, Prashasan Nagar, RD 72, Jubilee Hills, Hyderabad-500033, Telengana, India. Email: ksujatharao@outlook.com
} 
India still has nearly 50 million of its people sinking into poverty due to medical expenditures every year (National Health Systems Resource, 2016).

An issue related to inadequate funding is the spending priorities. Though in money terms international assistance to India has been negligible at about $2 \%$ of total health spending, it has profoundly impacted on agenda setting and has been driving the meager investments toward disease control programmes, such as malaria, tuberculosis and HIV/AIDS. Historically, international assistance to India went through two phases. In the initial years of independence from British rule, India depended on bilateral aid to shore up its capacity to cope with the high load of communicable diseases. This resulted in the elimination of small pox, guinea worm and vaccine preventable diseases like polio, and reduced overall morbidity and mortality due to communicable diseases. Thus, e.g., the reduction in incidence of HIV/AIDS by $57 \%$ and the increase in the number of HIV patients on ART to over 800,000 during 2000-2012 were largely a result of liberal multilateral funding from the World Bank and the Global Fund to Fight AIDS, tuberculosis and malaria. But even here, India sought to gain ownership. For instance, when I took over as Director General of the National AIDS Control Organization in 2006, international assistance covered almost $98 \%$ of the USD 500 million AIDS programme. This fell to $75 \%$ during the plan cycle 2007-2012, while the plan scaled up fivefold to USD 2.5 billion. Despite a similar overall level for the plan cycle 2012-2017, international support is currently less than $20 \%$.

The second phase of international funding was in post 1990s, when India availed of big investments from the World Bank for building its health infrastructure at the sub-district levels. This enabled scaling up institutional deliveries and reducing maternal and infant mortality. Yet, in view of inadequate public health spending, large swathes of the country continue to face severe supply side deficiencies. In numerous areas, the needed infrastructure and human resources are absent, and this is particularly the case in regions that together account for $40 \%$ of the country's population and $70 \%$ of maternal, infant and under-5 mortality. These are regions that have poor fiscal capacity to raise resources, weak governance, poor absorption capacity, high levels of corruption and the largest concentration of the poor in India.

The lesson emerging from the above is that while India found the money for programmes aimed at containing vertically driven communicable diseases in line with international agenda setting, it fell short in building its health system, which would require a far greater commitment of resources. Further, due to lack of clarity in what universal health coverage (UHC) implies, it paradoxically resulted in the further withdrawal of the government from critical investments in prevention and population health, as emphasis was put on providing expensive hospital treatment through insurance with the government paying the premium for the poor. This has contributed to the current distortions, where expensive treatment including free dialysis - are offered in high-cost corporate hospitals, even as one and half million children under five die of diarrhoea every year. 
What emerges from the above is that even in countries where international aid flows may be limited, government policies are influenced by the agenda setting in global fora. Therefore, the redefining of the UHC under the Sustainable Development Goals as implying UHC for essential services is an important step in building benchmarks for ensuring that critical services are the first charge on public finances in both resource constrained environments and donor countries.

Undoubtedly, the language of universalism carries implications for a country like India where intra-country disparities and inequities in access to basic health care services are high. India is a paradox combining a low-, middle-income country status with low-income country indicators, where resources not only need to be scaled up, but also strategically invested and targeted toward marginalized population groups and backward areas. Likewise, international funding too needs to direct its spending to where there is need. Ignoring middle-income countries like India for international aid flows is therefore not an option, though it may raise a moral dilemma. Disqualifying countries like India, China and Nigeria on grounds of fiscal capacity would mean excluding an estimated $56 \%$ of under-5 deaths. Thus, assistance to countries that have the fiscal capacity but not the political will needs to be accompanied with conditionalities such as co-sharing costs, targeting the most needy, and linking assistance to outcomes and policies to assure accountability to and sustainability of gains achieved.

Resetting priorities toward UHC for essential services will necessarily imply greater efforts at mobilizing domestic resources as the gap cannot be met solely by depending on international aid. The process for countries like India that may have the financial muscle, will not be easy given the discouraging global investment environment and a steady rise in protectionism, adversely impacting trade flows and the much needed investments for infrastructure and generating jobs. For after all, India's growth in terms of GDP may be impressive, but given its huge population base, the per capita income is still a low of about USD 1500.

In addition to battling with competing priorities, raising public spending on health to $5 \%$ of GDP will require India to restructure its macroeconomic environment. Policies aimed at reducing fossil fuel subsidies, tax waivers to the corporate sector (estimated to $6 \%$ of GDP), control of tax evasion, and efforts to arrest capital flight (estimated to over 4\% of GDP) are all fraught with political challenges for the government. To make tough decisions may also be particularly difficult over the next few years, as the prime minister is seeking to regain majority in the parliament in the 2019 election. However, the government's recent efforts of simplifying, streamlining and improving the tax administration are likely to have a beneficial impact and enable increasing the tax to GDP ratio from the current $17 \%$ per cent to over $20 \%$. Efforts are also being made to work with other governments to bring in greater accountability in financial transactions and minimize the growth of tax havens.

Alongside mobilizing resources, India also needs to improve its standards of governance. Greater efficiencies and better outcomes will require policies aimed at decentralization, people's participation and the containment of corruption, 
particularly at the service delivery level. The potential gains from such efforts are indicated by WHO's estimate that developing countries lose $20-40 \%$ of their health spending to corruption and inefficiencies every year (reference to paper by Elovainio and Evans, 2017).

Raising standards of accountability for people's welfare and providing needed leadership and resources require evidence-based policies. The Global Framework for Health Financing discussed in this issue provides clear direction and the necessary arguments for the way ahead. This must be accompanied with political will and a belief that every individual, regardless of the place of birth, has a right to health and well-being.

\section{References}

Elovainio, R. and D. B. Evans (2017), 'Raising more domestic money for health: prospects for low and middle income countries', Health Economics, Policy and Law, 12(2): 139-157.

McIntyre, D., F. Meheus and J.-A. Røttingen (2017), 'What level of domestic government health expenditure should we aspire to for universal health coverage?', Health Economics, Policy and Law, 12(2): 125-137.

National Health Systems Resource (2016), 'National health accounts estimates for India (2013-14)'. National Health Systems Resource (NHSRC) Centre Ministry of Health and Family Welfare, Government of India, New Delhi, http://www.mohfw.nic.in/ WriteReadData/1892s/89498311221471416058.pdf.

Røttingen, J. A., T. Otttersen, A. Ablo, D. Arhin-Tenkorang, C. Benn, R. Elovainio, D. B. Evans, L. E. Fonseca, J. Frenk, D. McCoy, D. McIntyre, S. Moon, G. Ooms, T. Palu, S. Rao, D. Sridhar, J. Vega, S. Wibulpolprasert, S. Wright and B. M. Yang (2014), 'Shared Responsibilities for Health: A Coherent Global Framework for Health Financing', Final Report of the Centre on Global Health Security Working Group on Health Financing, Chatham House, London. 